\title{
Association studies using random and "candidate" microsatellite loci in two infectious goat diseases
}

\author{
Gabriela ObeXer-RufF ${ }^{a *}$, Ursula SATTLER ${ }^{\mathrm{a}}$, \\ Dominique MARTINez ${ }^{\mathrm{b}}$, Jean-Charles MAILlard ${ }^{\mathrm{b}}$, \\ Christophe Chartier $^{\mathrm{c}}$, Nasikat Saitbekova ${ }^{\mathrm{a}}$, \\ Marie-Louise GlowATZKI $^{\mathrm{a}}$, Claude GAILlARD ${ }^{\mathrm{a}}$ \\ ${ }^{a}$ University of Berne, Institute of Animal Genetics, \\ Nutrition and Housing, Berne, Switzerland \\ ${ }^{\mathrm{b}}$ Cirad-EMVT, Petit-Bourg, Guadeloupe, FWI, Montpellier, France \\ c Affsa, Laboratoire d'études et de recherches caprines, Niort, France
}

(Accepted 4 February 2003)

\begin{abstract}
We established a set of 30 microsatellites of Bovidae origin for use in a biodiversity study in Swiss and Creole goats. Additional microsatellites located within or next to "candidate" genes of interest, such as cytokine genes (IL4, INF-gamma) and MHC class II genes (DRB, DYA) were tested in the caprine species in order to detect possible associations with two infectious caprine diseases. Microsatellite analysis was undertaken using automated sequencers $(\mathrm{ABI} 373 \& 3100)$. In the first study, a total of 82 unrelated Creole goats, 37 resistant and 45 susceptible to Heartwater disease (Cowdriosis) were analysed. In this study, the two microsatellite loci DRBP1 (MHCII) and BOBT24 (IL4) were positively associated with disease susceptibility, demonstrating a corrected $P$-value of 0.002 and 0.005 , respectively. In a second investigation, we tested 36 goats, naturally infected with the nematode parasite Trichostrongylus colubriformis. These animals were divided into a "low" and "high" excreting group on the basis of two independently recorded fecal egg counts. For this nematode resistance study, we detected a significant association of one of the alleles of the microsatellite locus SPS113 with "low" excretion (resistance). The MHC class II locus DYA (P19), was weakly associated with susceptibility in both diseases $\left(P_{\mathrm{c}}=0.05\right)$. In future experiments, we will extend the sample size in order to verify the described associations.
\end{abstract}

disease association / microsatellites / goats

* Correspondence and reprints

E-mail: gabriela.obexer-ruff@itz.unibe.ch 


\section{INTRODUCTION}

In order to be able to conduct disease association studies in various goat populations, we used microsatellite primers of Bovidae origin known to show sufficient polymorphism in the caprine species $[9,10]$ because sequence polymorphisms of potential candidate genes were not known well enough in the goat. In addition, we tested microsatellites of the Bovidae origin located next to "candidate" genes of interest. By studying infectious diseases with immunogenetic and immunopathological components, such as Cowdriosis [4] and gastro-intestinal Nematode infection [5] in goats, we looked for microsatellites linked to genes controlling immune mediators such as the cytokines Interleukine 4 (IL4) [1] and Interferon-gamma (INFg) [7], playing a possible role in disease pathogenesis. Microsatellites linked to immuno-relevant loci as the Major Histocompatibility complex (MHC) [2] and the VbetaT-cell receptor $(\operatorname{TCRV} \beta)$ [3] locus were also included.

\section{MATERIALS AND METHODS}

\subsection{Animals}

For the Cowdriosis study, a total of 82 unrelated (37 classified resistant, 45 susceptible) experimentally challenged animals [4] with Cowdria ruminantium were tested. In the nematode resistance study, a total of 155 multiparous, lactating French alpine goats (2-4 years old) were naturally pasture-infected, predominantely with the parasite Trichostrongylus colubriformis. These animals were divided into a "low" and "high" excreting group on the basis of two (July and October) independently recorded fecal egg counts, and the 20 extreme animals of each group were selected for genotyping. Parentage data were only available for two generations, and no full- or half-sibs were chosen.

\subsection{Fecal egg counts}

The differences between the two groups: high and low excreting goats were highly significant $(P<0.001)$ at each date with low excreting goats showing $200 \pm 107$ (mean \pm SD) egg output per gram of faeces (opg) in July (range: $0-350$ ) and $340 \pm 160 \mathrm{opg}$ in October (range: 50-550). Corresponding results for high excreting goats were $1181 \pm 309$ opg in July (range: 750-1700) and $1462 \pm 337$ opg in October (range: 1000-2100). Also, fecal egg output per gram of faeces was higher in October than in July $(P=0.02)$.

\subsection{Loci PCR primers and conditions}

Genomic DNA was extracted from EDTA-blood using the Roche Diagnostics ${ }^{\circledR}$ High Pure PCR Template Preparation kit. We used 24 random 
microsatellite primers that were developed in Bovidae $[9,10]$ and 6 microsatellite primers located next to "candidate" genes of interest [1-3,7]. PCR amplification of the fluorescently-labelled microsatellites was performed on Geneamp 9600 and 9700 (Perkin Elmer) thermocyclers [1-3,7,9-11].

\subsection{Genotyping}

Genotyping was carried out on automated DNA sequencers ABI 373 and ABI 3100. Allele sizes were determined with ABI Genescan ${ }^{\circledR}$ and Genotyper ${ }^{\circledR}$ software.

\subsection{Statistical analysis}

Statistical analyses were performed using the GENEPOP [8] and SAS ${ }^{\circledR}$ Inst. Inc., Software Release 8.2 programmes.

\section{RESULTS}

\subsection{Cowdriosis}

In the Cowdriosis study, the two microsatellite loci DRBP1 (MHCII) and BOBT24 (IL4) were positively associated with disease susceptibility, demonstrating a corrected $P$-value $\left(P_{\mathrm{c}}\right)$ of 0.002 and 0.005 after Bonferroni correction, respectively for the alleles 2 and 1 (Fig. 1a and 1b). Significant frequency differences for alleles 1 and 4 of the microsatellite linked to INFg were found between the resistant and susceptible groups. However, these significances did not hold after the Bonferroni correction. Both alleles were found at a relatively low overall frequency $(0.04$ and 0.06$)$ in the total population (Fig. 2).

\subsection{Nematode-resistance}

In the nematode resistance study a significant association $(P=0.005)$ was found with the microsatellite locus SPS113. The group with low-excretion of nematode eggs showed a frequency of allele 4 of 0.34 whereas in the group with the high-excreting animals, this respective frequency was only 0.03 (Fig. 3). The DYA (P19) MHC class II locus, was weakly associated with susceptibility in both diseases $\left(P_{\mathrm{c}}=0.05\right)$.

\section{DISCUSSION}

\subsection{Cowdriosis}

The difference of allele frequencies at the MHC class II loci, DRBP1 and DYA, between the resistant and susceptible groups in the Cowdriosis population 


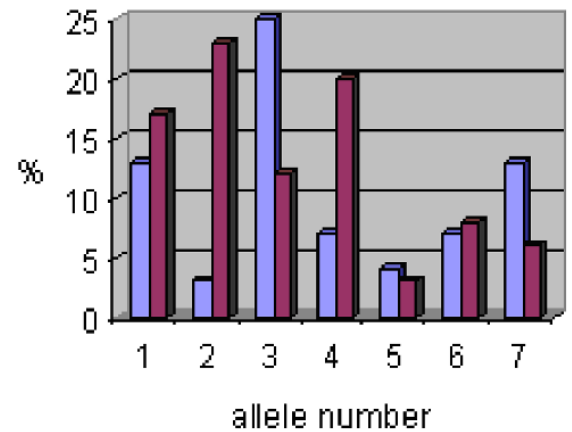

(a)

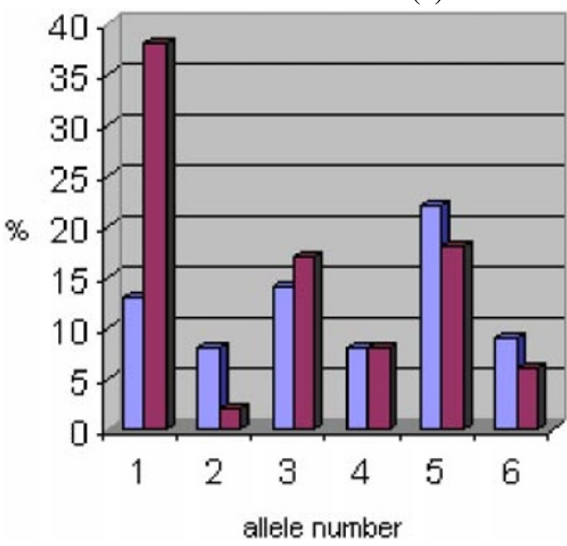

(b)

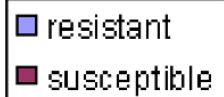

$\square$ resistant

asusceptible

Figure 1. (a) Allele frequencies of microsatellite DRBP1 in Creole goats resistant/susceptible to Heartwater disease (Cowdriosis). Allele 2: Chi-Square $=14.1$ $\left(P_{\mathrm{c}}=0.002\right)$. (b) Allele frequencies of microsatellite BOBT24 (IL4) in Creole goats susceptible/resistant to Heartwater disease (Cowdriosis). Allele 1: Chi-Square $=11.5$ $\left(P_{\mathrm{c}}=0.005\right)$.

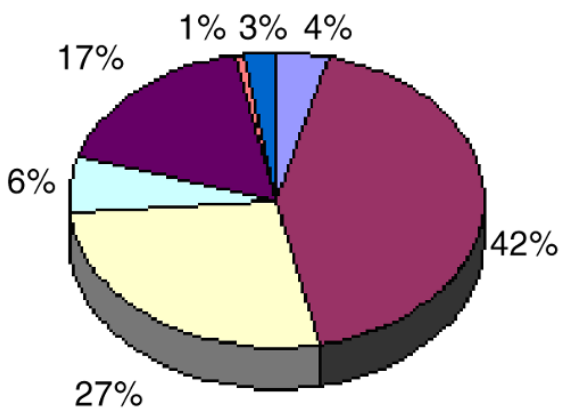

\begin{tabular}{|l|}
\hline$\square$ Allele1 \\
$\square$ Allele2 \\
$\square$ Allele3 \\
$\square$ Allele4 \\
$\square$ Allele5 \\
$\square$ Allele6 \\
$\square$ Allele7
\end{tabular}

Figure 2. Allele frequencies of microsatellite OARKP6 (INFg) in the Creole goat population $(\mathrm{N}=59)$. 


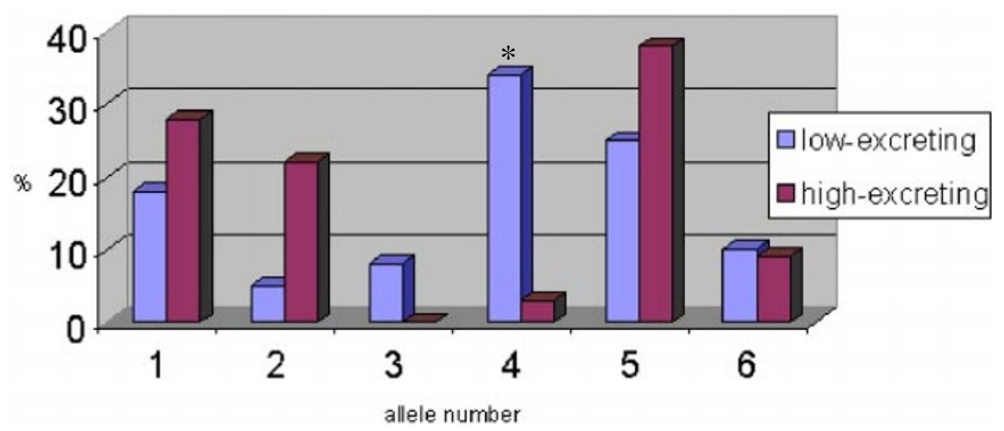

Figure 3. Allele frequencies of microsatellite SPS113 in nematode-infected Alpine goats. *Allele 4: Chi-Square $=11.0\left(P_{\mathrm{c}}=0.005\right)$.

study indicated a possible influence of the $\mathrm{MHC}$ region as we also demonstrated by serological MHC class I typing in a previous study [4]. The detected association could not be demonstrated in family material up to now. Through the cross-breeding programme [4], originally started by the Cirad/EMVT, it was not possible to generate sufficient offspring for statistical analyses of the respective resistant/susceptible groups. Two of the included presumed "susceptible" sires, originating from a non-endemic area had to be classified "resistant" after challenge. At present, it is not planned to extend the breeding programme.

The frequency differences for alleles 1 and 4 of the microsatellite linked to the INFg locus [7] were not significant after correction of the $P$-value, due to the overall low frequency of these alleles. We plan to include the respective microsatellite in the course of a vaccination trial of Creole goats, where interferon-gamma excretion and intracellular interferon-gamma will be measured and possibly related to the disease phenotypes. Individual high INFg levels were phenotypically correlated with survival [11].

In addition, we tested an ovine microsatellite located near the naturalresistance-associated macrophage protein (NRAMP) genes [6], a locus of possible importance in the early or innate phase of the immune response of intracellular bacterial infections like Cowdriosis. The low number of alleles $(\mathrm{N}=3)$ found for the Creole goats, however, did not allow finding any significant allele frequency differences between the resistant and the susceptible goats (data not shown).

\subsection{Nematode resistance}

The association of microsatellite SPS113 detected for the "low-excretion" group in the nematode-infection study will be further investigated in family material. A possible "sire effect" cannot be excluded in the present data, due 
to relatively limited parentage information. We do not know of any other previous report on a positive association of this microsatellite with nematode resistance. It was included it our analysis because it belonged to the multiplex PCR together with the INFg locus, and was used for parentage control in goats.

The microsatellites described in our study which are located next to genes of immuno-pathological relevance might be of interest for other disease association studies carried out in the caprine species. In the course of an ongoing European biodiversity study (P. Ajmone Marsan, coordinator ${ }^{1}$ ) for small ruminants, several genes of possible importance in fitness and disease will be screened for polymorphism (SNPs) in various local sheep and goat breeds. With the development of new polymorphism tools, disease association studies will become possible by focusing directly on the genes themselves.

\section{ACKNOWLEDGEMENTS}

This work was supported by the Swiss Federal Office for Education and Science (BBW) grants No. 95.0614 and 99.0704 to GO-R.

\section{REFERENCES}

[1] Buitkamp J., Obexer-Ruff G., Kressler M., Epplen J.T., A microsatellite (BOBT24) located between the bovine IL-4 and IL-13 is polymorphic in cattle and goat, Anim. Genet. 27 (1996) 212-213.

[2] Buitkamp J., Filmether P., Stear M.J., Epplen J.T., Class I and class II major histocompatibility complex alleles are associated with faecal egg counts following natural predominantly Ostertagia circumcincta infection, Parasitol. Res. 82 (1996) 693-696.

[3] Buitkamp J., Schwaiger F.W., Epplen J.T., Vb6 T-cell receptor elements in artiodactyls: conservation and germline polymorphisms, Mamm. Genome 4 (1996) 504-510.

[4] Camus E., Maillard J.-C., Ruff G., Pepin L., Naves M., Matheron G., Genetic resistance of Creole goats to cowdriosis in Guadeloupe: Status in 1995, Ann. New York Acad. Sci. 791 (1996) 46-53.

[5] Chartier C., Hoste H., Response to challenge infection with Haemonchus contortus and Trichostrongylus colubriformis in dairy goats: differences between high and low producers, Vet. Parasitol. 73 (1997) 267-276.

[6] Matthews G.D., Crawford A.M., Cloning, sequencing and linkage mapping of the NRAMP1 gene of sheep and deer, Anim. Genet 29 (1998) 1-6.

[7] Paterson K.A., Crawford A.M., Ovine microsatellite OarKP6 from a BAC containing the ovine interferon gamma gene, Anim. Genet. 31 (2000) 343.

[8] Raymond M., Rousset F., GENEPOP (version 1.2) - Population genetics software for exact tests and ecumenicism, J. Hered. 86 (1995) 248-249.

${ }^{1}$ http://lasig.epfl.ch/projets/econogene. 
[9] Saitbekova N., Gaillard C., Obexer-Ruff G., Dolf G., Genetic diversity in Swiss goat breeds based on microsatellite analysis, Anim. Genet. 30 (1999) 36-41.

[10] Stahlberger-Saitbekova N., Schläpfer J., Dolf G., Gaillard C., Genetic relationships in Swiss sheep breeds based on microsatellite analysis, J. Anim. Breed. Genet. 118 (2001) 379-387.

[11] Totté P., Blankaert D., Zilimwabagabo X., Werenne J., Inhibition of Cowdria ruminantium infectious yield by INFalpha and gamma in endothelial cells, Rev. Elev. Med. Vet. Pays Trop. 46 (1993) 189-194.

To access this journal online: www.edpsciences.org 